\title{
Erratum to: Methodology for the analysis of causes of drought vulnerability on the River Basin scale
}

\author{
Jesús $\operatorname{Vargas}^{1}$ (D) Pilar Paneque ${ }^{2}$
}

\section{Erratum to: Nat Hazards \\ DOI: $10.1007 / \mathrm{s} 11069-017-2982-4$}

Due to an oversight during the editorial process, the title and abstract were given in Spanish in the original online publication of the article. The original article has been corrected.

The online version of the original article can be found under doi:10.1007/s11069-017-2982-4.

Jesús Vargas

Jvarmol@upo.es

Pilar Paneque

Ppansal@upo.es

1 Geography Laboratory, Pablo de Olavide University of Seville, 1 Utrera Road, Building 44, Lab 44, B04, Seville, Spain

2 Human Geography Departament, Pablo de Olavide University of Seville, 1 Utrera Road, Building 2, Seville, Spain 